\title{
Environmental Management Welcomes a New Face and Reinforces Its Focus on Science-Based Stewardship
}

\author{
Virginia H. Dale
}

Published online: 4 June 2010

(C) US Government 2010

ENVIRONMENTAL MANAGEMENT is pleased to announce that Rebecca Efroymson will join Virginia Dale as Co-Editors-in-Chief of the journal. Dr. Efroymson brings extensive expertise in risk assessment and environmental toxicology. Her work has focused on land management, natural resources, water quality, and rare species, with recent work on benefits and risks of energy alternatives.

ENVIRONMENTAL MANAGEMENT has been publishing research on the management and conservation of natural resources and habitats since 1976. Articles discuss implications for an international audience and examine a scientific or management hypothesis. As a premier scientific journal in applied and cross-cutting areas, articles come from a variety of disciplines including biology, botany, climatology, earth sciences, ecology, ecological economics, environmental engineering, fisheries, forest sciences, geography, information science, law, management science, politics, public affairs, social sciences, and zoology, most often in combinations determined by the interdisciplinary topic of the study. The journal strives to improve cross-disciplinary communication by making ideas and results available to environmental practitioners from other backgrounds.

The goal of ENVIRONMENTAL MANAGEMENT is to present a wide spectrum of viewpoints and approaches, and to this end the journal consists of four main sections. Forum contains addresses, editorials, comments, and opinions about environmental matters. Articles in the
Profile section describe and evaluate particular case histories, events, policies, problems, or organizations and their work. Papers in the Research section present the methods and findings from empirical and model-based scientific studies. The section on Environmental Assessment is for articles that cover methods of appraisal, measurement, and comparison. Generally, the debates published in the journal's Forum help construct better environmental research or policies; Research and Assessment sections foster understanding of environmental problems and usually of their solutions; and Profile articles may contribute to either aim, or both. In the event that important differences of opinion cannot be resolved between authors and referees or readers, the Forum section may be used to present a Comment on an article that has recently been published in the journal, which may be followed by the author's Reply.

The journal publishes innovative research that both identifies new problems and formulates novel solutions to well-known ones. Articles are accepted from all over the world, as the international dimension is considered especially important. Research reported in the journal ranges from environmental problems that are common to a wide variety of nations to issues that are either of global concern or not limited to national boundaries. The journal provides a way for scientists to share approaches, methods, and experiences among environmental practitioners in many countries, so that the problems and opportunities of our ever more-interdependent planet may be studied in a concerted manner.
V. H. Dale $(\bowtie)$

Oak Ridge National Laboratory, Bethel Valley Road, Building 1505, Room 200, P.O. Box 2008, Oak Ridge, TN 37831-6036, USA

e-mail: dalevh@ornl.gov 